\title{
Genetic identification and hybridization in the seagrass genus Halophila (Hydrocharitaceae) in Sri Lankan waters
}

\author{
Shang Yin Vanson Liu ${ }^{\text {Corresp., }, ~ 2,3}$, Terney Pradeep Kumara ${ }^{4}$, Chi-Hsuan Hsu ${ }^{1}$ \\ 1 Department of Marine Biotechnology and Resources, National Sun Yat-Sen University, Kaohsiung, Taiwan \\ 2 Doctoral Degree Program in Marine Biotechnology, National Sun Yat-Sen University, Kaohsiung, Taiwan \\ 3 Graduate Institute of Natural Products College of Pharmacy, Kaohsiung Medical University, Kaohsiung, Taiwan \\ 4 Department of Oceanograhy and Marine Geology, University of Ruhuna, Matara, Sri Lanka \\ Corresponding Author: Shang Yin Vanson Liu \\ Email address: syvliu@mail.nsysu.edu.tw
}

Seagrasses, as marine angiosperms, play important roles in coastal ecosystems. With increasing anthropogenic impacts, they are facing dramatic declines on a global scale. Halophila is well-known as a complex taxonomic challenge mainly due to high morphological plasticity. By using only a morphological approach, the genus could be oversplit or similar species could be erroneously lumped, thus masking its true biodiversity. In the present study, we incorporated genetic identification with morphological examination to reveal the identity of Halophila plants in southern and northwestern Sri Lankan waters. The nuclear ribosomal internal transcribed spacer (ITS) region and chloroplast ribulosebisphosphate carboxylase gene ( $r b c L)$ were used to identify plants collected from the Gulf of Mannar, Puttalam Lagoon, and Matara, Sri Lanka. Based on genetic identification, $H$. major (Zoll.) Miquel is reported for the first time from Sri Lanka, which might have been misidentified as $H$. ovalis in previous literature based on morphology alone. We also observed a first hybridization case of Halophila cross between $H$. ovalis and $H$. major. Two potential cryptic species were found, herein designated Halophila sp. 1 (allied to H. minor) and Halophila sp. 2 (closely related to $H$. decipiens). In order to clarify taxonomic ambiguity caused by morphological plasticity and the low resolution of genetic markers, further comparative phylogenomic approaches might be needed to solve species boundary issues in this genus. 
1 Genetic identification and hybridization in the seagrass genus Halophila (Hydrocharitaceae)

2 in Sri Lankan waters

3

4

5 Shang Yin Vanson Liu ${ }^{1,2,3^{*}}$, Terney Pradeep Kumara ${ }^{4}$, Chi-Hsuan Hsu ${ }^{1}$

$6{ }^{1}$. Department of Marine Biotechnology and Resources, National Sun Yat-Sen University,

7 Kaohsiung 80424, Taiwan

8 2. Graduate Institute of Natural Products College of Pharmacy, Kaohsiung Medical University,

9 Kaohsiung, 807 Taiwan

10 3. Doctoral Degree Program in Marine Biotechnology, National Sun Yat-Sen University,

11 Kaohsiung 80424, Taiwan

124 . Department of Oceanograhy and Marine Geology, University of Ruhuna, Sri Lanka.

13

14

15

* Corresponding author

16

Shang Yin Vanson Liu

17 No.70 Lien-hai Rd., Kaohsiung 80424, Taiwan, R.O.C.

18 Email: syvliu@mail.nsysu.edu.tw

19

20

21

22

23

24

25

26

27

28

29

Peer) reviewing PDF | (2020:04:47375:1:1:NEW 11 Aug 2020) 
30

31

32

33

34

35

36

37

38

39

40

41

42

43

44

45

46

47

48

49

50

51

52

53

54

55

56

57

58

59

60

\section{Abstract}

Seagrasses, as marine angiosperms, play important roles in coastal ecosystems. With increasing anthropogenic impacts, they are facing dramatic declines on a global scale. Halophila is wellknown as a complex taxonomic challenge mainly due to high morphological plasticity. By using only a morphological approach, the genus could be over-split or similar species could be erroneously lumped, thus masking its true biodiversity. In the present study, we incorporated genetic identification with morphological examination to reveal the identity of Halophila plants in southern and northwestern Sri Lankan waters. The nuclear ribosomal internal transcribed spacer (ITS) region and chloroplast ribulose-bisphosphate carboxylase gene ( $\mathrm{rbcL}$ ) were used to identify plants collected from the Gulf of Mannar, Puttalam Lagoon, and Matara, Sri Lanka. Based on genetic identification, H. major (Zoll.) Miquel is reported for the first time from Sri Lanka, which might have been misidentified as H. ovalis in previous literature based on morphology alone. We also observed a first hybridization case of Halophila cross between $H$. ovalis and $H$. major. Two potential cryptic species were found, herein designated Halophila sp. 1 (allied to H. minor) and Halophila sp. 2 (closely related to H. decipiens). In order to clarify taxonomic ambiguity caused by morphological plasticity and the low resolution of genetic markers, further comparative phylogenomic approaches might be needed to solve species boundary issues in this genus.

\section{Introduction}

Seagrasses, a functional group of marine flowering plants found in coastal areas of the world's oceans, provide essential habitat for many coastal species and support marine food webs, playing critical roles in the balance of coastal ecosystems and human livelihoods (Mtwana Nordlund et al. 2016). It has been shown that seagrass habitat declined worldwide at a rate of $110 \mathrm{~km}^{2}$ per year between 1980 and 2006 (Waycott et al., 2009). Short et al. (2011) suggested 72 seagrass species needed to be listed in the Red List of International Union for the Conservation of Nature (IUCN) based on global population status. Therefore, there is an urgent need to conduct baseline studies (i.e., diversity, abundance, and distribution) for establishing conservation plans in the future.

7 However, identification based on morphological traits in the genus Halophila is considered to be

8 very challenging since few morphological differences or characteristics exist among closely related species (Kuo et al. 2006). Field ecologists without taxonomic knowledge of this genus may either overestimate or underestimate its true biodiversity (Shimada et al., 2012; Tuntiprapas 
61

62

63

64

65

66

67

68

69

70

71

72

73

74

75

76

77

78

79

80

81

82

83

84

85

86

87

88

89

90

91

et al., 2015; Kurniawan et al., 2020).

The genus Halophila comprises approximately 20 species within five sections based on morphological differences (Den Hartog \& Kuo 2006; Kuo et al. 2006). Most species in the genus are in section Halophila, which contains species with a pair of petiolate leaves borne on short, erect lateral shoots (Den Hartog \& Kuo 2006; Kuo et al. 2006). All other species are in sections Microhalophila (H. beccarii), Spinulosae (H. spinulosa), Tricostata (H. tricostata), and Americanae (H. engelmannii and H. baillonis). However, molecular genetic studies propose that H. hawaiiana and H. johnsonii should be treated as conspecific with H. ovalis (Short et al. 2010). The ITS (internal transcribed spacer) sequence is proven to have great resolution for acting as a genetic barcode for the genus Halophila (Kim et al. 2017). Kim et al. (2017) showed that five major clades can be identified in section Halophila, which has relatively simple phyllotaxy compared to other sections. However, five morphologically similar species cannot be distinguished in the Halophila ovalis complex with ITS: H. ovalis, H. minor, H. hawaiiana, $H$. johnsonii, and $H$. ovata. On the other hand, that section's ITS region is capable of identifying $H$. decipiens, H. major, H. nipponica, H. okinawensis, H. guidichudii, and H. stipulacea. On the other hand, the rbcL (ribulose-bisphosphate carboxylase) gene of the chloroplast is suggested as a potential barcode region for land plants since it can discriminate among species in approximately $85 \%$ of congeneric pair-wise comparisons (Newmaster et al. 2006). For seagrasses, the combined use of rbcL and matK (maturase $\mathrm{K}$ ) genes is recommended by the Consortium for the Barcoding of Life (CBOL). However, neither the resolution of rbcL alone or the combination of $\mathrm{rbcL}$ and matK can well resolve the phylogenetic relationship of closely related species within the genus Halophila (Nguyen et al. 2015). Since Halophila species have notoriously great morphological plasticity, ITS and $\mathrm{rbcL}$ resolution incorporated with detailed morphological examination should provide valuable insight on the biodiversity of the genus in Sri Lanka.

Fourteen species belonging to six genera (60\% of Indo-Pacific bioregion seagrasses) have been recorded in Sri Lanka: Enhalus acoroides, H. beccarii, H. decipiens, H. ovalis, H. ovata, H. minor, H. stipulacea, Thalassia hemprichii, Cymodocea rotundata, C. serrulata, Halodule uninervis, H. pinifolia, Ruppia maritima, and Syringodium isoetifolium (Udagedara et al. 2017). Among these, H. ovalis, H. ovata, and H. minor belong to the H. ovalis complex, which is very difficult to differentiate by morphological traits. Udagedare et al. (2017) have also mentioned 
92 that the distribution records of seagrasses in the Sri Lankan coast are extremely limited due to

93 three decades of civil conflict ending in 2009 and a concurrent severe decline in seagrasses. A 94 recent study showed that species composition changed and biodiversity decreased from 1991 to 952013 at Puttalam Lagoon in association with human activities (Ranahewa et al. 2018). Therefore, 96 there is an urgent need to understand the distribution and diversity of seagrasses in Sri Lankan 97 waters before local extinctions occur.

98 In the present study, we incorporate morphological and genetic analyses on plants belonging to 99 the genus Halophila collected from Sri Lankan waters that are difficult to identify by using either 100 approach alone. With this integration, we attempt to reveal potentially overlooked biodiversity 101 and species distribution.

102

\section{Materials \& Methods}

104 Sampling and phylogenetic analyses

105 Halophila samples were collected by either snorkeling or sampling from the shoreline in early 106 December 2018 under the permission No. NIC:196931003193 from three sites at depths from 0.5 $107 \mathrm{~m}$ to $2 \mathrm{~m}$ based on occurrence data in previous literature and information from local fishermen: 108 the Gulf of Mannar (N = 32; GPS: 8.9753739N, 79.9224197E), Puttalam Lagoon, Kalpitiya (N = 109 32; GPS: $8.3671739 \mathrm{~N}, 79.785565 \mathrm{E}$ ), and Matara ( $=33$; GPS: $5.9474017 \mathrm{~N}, 80.6349298 \mathrm{E})$

110 (Figure 1). The former two locations are within a lagoon system having very low visibility $(<20$ $\mathrm{cm})$. Halophila plants collected from Puttalam were scattered below a huge meadow of Thalassia hemprichii that occurred along the lagoonal side of a sandbar. We collected Halophila plants only from the shoreline at Mannar, since the water is highly polluted by households.

114 Conversely, the site in Matara where we collected Halophila plants faces a coastal ocean area 115 dominated by a $10 \times 50 \mathrm{~m} \mathrm{H}$. major meadow having $>5 \mathrm{~m}$ visibility. Leaves were preserved in 116 silica gel for further DNA extraction. Genomic DNA were extracted from leaves using a Plant 117 Genomic DNA Mini Kit (Geneaid Biotech, Taipei, Taiwan). The two markers used in the present 118 study were the rbcL gene from chloroplast DNA and nuclear ITS1-5.8S-ITS2. Primer pairs used 119 in this study were P609 5'- GTAAAATCAAGTCCACCRCG -3'and P610 5'-

120 ATGTCACCACAAACAGAGACTAAAGC -3' for rbcL (Lucas et al. 2012) and ITS5a 5'121 CCTTATCATTTAGAGGAAGGAG-3' and ITS4 5'-TCCTCCGCTTATTGATATGC-3' for 122 ITS1-5.8S-ITS2 (Nguyen et al. 2014). 
123 Two loci were amplified in $25 \mu \mathrm{L}$ reactions in a gradient thermocycler (Veriti 96-well thermal 124 cycler, Thermo Fisher Scientific) over an initial denaturation step at $95^{\circ} \mathrm{C}$ for $3 \mathrm{~min}, 30$ cycles 125 of denaturation at $94{ }^{\circ} \mathrm{C}$ for $30 \mathrm{~s}$, annealing at $50^{\circ} \mathrm{C}$ (ITS1-5.8S-ITS2) and $57^{\circ} \mathrm{C}(\mathrm{rbcL})$ for $30 \mathrm{~s}$, 126 extension at $72{ }^{\circ} \mathrm{C}$ for $1 \mathrm{~min}$, with a final extension step at $72{ }^{\circ} \mathrm{C}$ for $5 \mathrm{~min}$. Each reaction 127 contained $30 \mathrm{ng}$ template DNA, $12.5 \mathrm{ul}$ 2X master Mix RED (15 mM MgCl, $0.4 \mathrm{mM}$ each 128 dNTPs, $200 \mathrm{nM}$ of each primer, 0.2 unit of Ampliqon DNA polymerase (Ampliqon, Denmark) 129 and dd water was added to make a final volume of 25 ul. PCR products were sent to Genomics 130 (New Taipei City, Taiwan) for sequencing by an ABI 377 automated sequencer (Carlsbad CA, 131 U.S.A.).

132 Known ITS sequences and rbcL from other Halophila species were added to the dataset for 133 comparison (Table S.1). Sequences obtained in the present study were aligned with reference 134 sequences, including those within sections Spinulosae, Tricostata, Microhalophila, and 135 Americanae as outgroups by MEGA 7 (Tamura et al., 2013) to visually inspect all alignments as well as search for the best nucleotide mutation model. Phylogenetic analyses were performed to reveal genetic divergences among Halophila plants collected from different geographic locations, with Bayesian inference assessments through $\mathrm{Mr}$ Bayes (MB) version 3.2.2 (Ronquist et al., 2012) and maximum likelihood (ML) being performed by CIPRES Science Gateway (Miller et al., 2015). The former implemented two parallel runs of four simultaneous Markov chains for 10 million generations, sampling every 1000 generations and using default parameters. We discarded the first million generations $(10 \%)$

143 as burn-in, based on the stationarity of log-likelihood tree scores. ML analyses were conducted in 144 RAxML version 8.1.24 (Stamatakis, 2014) on CIPRES Science Gateway with default settings.

145 Supporting value on the branches were evaluated by non-parametric bootstrapping with the 146 automatically halt bootstrapping option by RAxML (ML).

\section{Molecular cloning}

148 Among the three sites, a majority of the plants (22/32) collected from Puttalam Lagoon, 149 Kalpitiya, failed to sequence on the ITS1-5.8S-ITS2 region due to multiple templates. We then 150 obtained pure ITS1-5.8S-ITS2 sequences by using molecular cloning.

151 ITS1-5.8S-ITS2 PCR products amplified from SB21, SB22, SB23, and SB 24 were ligated into 152 pJET1.2/blunt vector and cloned using a CloneJet PCR cloning kit (Thermo Scientific, U.S.A.). 153 In total, 17 positive clones were selected for further PCR reaction. The final cloned PCR 
154 fragments were sequenced by Genomics (New Taipei City, Taiwan) using pJET1.2 forward and 155 reverse primers. All sequences derived from the present study were submitted to GenBank under 156 accession Nos. MT347850-MT347937 (ITS) and MT422621-MT422718 (rbcL).

157

158

\section{Morphological analyses}

159

160

One mature leaf was taken from 48 different plants in each category, comprising H. major, H. sp. 161 162 1 (allied to H. minor), H. ovalis, hybrids, potential hybrids, and Halophila sp. 2 (H. decipiens like) (Table 1), for morphological measurements consisting of lamina width, lamina length, distance from intramarginal vein to lamina margin, cross-vein angle, and number of cross-veins (Figure S. 1). We calculated the ratio between intramarginal veins to the edge and the half-length 165 of the width, and the ratio between lamina width and length. Specimens were identified using the keys of Den Hartog and Kuo (2007) and Kuo et al. (2006). Morphological data were transformed (x-mean/standard deviation) and subjected to PCA to find out the variation among categories using Past3 software (Hammer et al., 2001).

\section{Results}

171 Phylogenetic analyses

172 For the ITS1-5.8S-ITS2 region, only 59 of 97 plants were successfully sequenced, 38 failing to 173 achieve consensus sequencing due to the multiple template effect. We subsequently selected four samples for molecular cloning and obtained 17 sequences of the ITS1-5.8S-ITS2 region. In total, with 24 sequences obtained from GenBank and two sequences from $H$. decipiens collected from southern Taiwan, 14 valid species of Halophila were represented. In total 112 sequences were used for alignment and phylogenetic analyses. The length of aligned sequences is $615 \mathrm{bp}$, with 157 parsimony informative sites. Based on the ITS phylogenetic tree, sequences in the present study can be divided into three highly supported clades, which are H. major, the H. ovalis complex, and a potential new species (Halophila sp. 2) that is closely related to H. decipiens in terms of anatomic structure as seen under a SEM (J Kuo \& S Liu, 2020, unpublished data). Interestingly, fresh plants of Halophila sp. 2 are very similar to H. stipulacea (Figure S. 2). Outgroups are in sections Microhalophila (H. beccarii), Spinulosae (H. spinulosa), Tricostata (H. tricostata), and Americanae (H. engelmannii), which have complicated phyllotaxy and can 
185 clearly be separated from species having simple phyllotaxy in section Halophila, except $H$. 186 australis. The basal clades of the ingroup comprised three species having leaf edge serrations, 187 including H. stipulacea, H. decipiens, and Halophila sp. (H. stipulacea like clade). Sequences 188 derived from plants collected from all three Sri Lankan sites fell into two main clades: the $H$. 189 ovalis complex clade and $H$. major clade. Sequences clustering in the $H$. major clade were 190 mainly from Mannar and Matara, whereas sequences clustering in the H. ovalis complex clade

191

192 193

194 195 196

197 198 199

200

201

202

203

204 205

206

207

208

209

210

211

212

213

214

215 were from Mannar and Puttalam Lagoon. Interestingly, sequences derived from molecular cloning showed that any given plant contained ITS sequences of both $H$. ovalis and $H$. major, as shown in Figure 2. For example, six sequences were obtained from SB24, two of them belonging to the $H$. major clade and the remainder to the $H$. ovalis complex clade. This may indicate a possible hybrid cross between $H$. ovalis and $H$. major.

Only one of the 97 samples failed to amplify rbcL. With eight sequences downloaded from GenBank representing seven species of Halophila, the length of the final alignment was $440 \mathrm{bp}$ with only six parsimony informative sites. $H$. beccarii and $H$. engelmannii served as outgroups. At the basal-most position of the ingroup, Halophila sp. 2 clustered with a sequence derived from a sample collected from India that was identified as $H$. stipulacea and sister to $H$. decipiens. However, sequences derived from most Sri Lankan samples formed a monophyletic clade along with references identified as H. ovalis, H. major, and H. minor (Figure 3). Since rbcL lacked genetic variation among the different Halophila species, the unresolved phylogeny indicates that rbcL cannot resolve species boundaries in Halophila.

\section{Morphological analyses}

We were unable to measure all the plants that we collected in the present study because we did not collect enough shoots for both DNA extraction and morphological examination during sampling. After DNA extraction, we were able to measure 48 plants, which were further defined into six categories comprised of potential hybrid (failure to sequence without further cloning due to multiple templates), hybrid, H. ovalis, Halophila sp. 1 (allied to H. minor), H. major, and Halophila sp. 2 (H. decipiens like) (Figure 4). The number of plants examined and results of five measurements and two ratios are given in Table 1. Raw data were transformed and a principal component analysis (PCA) was performed. Variance explained by the first two PCA components (PCA1 and PCA2) is $79.576 \%$. The majority of the variance (95\%) of PCA-1 and PCA-2 was explained by lamina length and lamina width:lamina length, respectively. The result of the PCA 
216 plot shows that Halophila sp. 1 (allied to H. minor) and Halophila sp. 2 can be distinguished 217 from other categories by smaller lamina length and smaller lamina width:lamina length, 218 respectively. H. major had the widest distribution in the PCA plot, and the hybrid and potential 219 hybrid fell within the range of H. ovalis and H. major (Figure 5).

220

\section{Discussion}

222 The literature related to seagrass communities and biodiversity in the Sri Lanka is scarce. 223 Jayasuriya (1991) mentioned that there are 12 species among nine genera recorded from Sri 224 Lanka, the number being increased to 15 in 2007 (De Silva \& Amarasinghe, 2007). The latest 225 report showed 14 species as of 2017 (Udagedara et al., 2017), with the complete list being 226 Enhalus acoroides, Halophila beccarii, H. decipiens, H. ovalis, H. ovata, H. minor, $H$. 227 stipulacea, Thalassia hemprichii, Cymodocea rotundata, C. serrulata, Halodule uninervis, $H$. 228 pinifolia, Ruppia maritima, and Syringodium isoetifolium. In the present study, H. major 229 (Zollinger) Miquel (1855) is a new species record for Sri Lanka based on genetic analyses. $H$. 230 major was previously treated as a synonym of $H$. ovalis by den Hartog (1970), and in 2006 Kuo (2006) examined global type materials and concluded that reinstating the taxon status of $H$. major was warranted. Additionally, further phylogenetic studies (Uchimura et al., 2008; Nguyen et al., 2013) showed molecular evidence that $H$. major can also be separated from H. ovalis by using the ITS region. Kuo (2006) suggested that $H$. major and $H$. ovalis can be distinguished by a ratio of $1 / 2$ of the lamina width to the distance between the intramarginal veins and lamina margin, and the number of cross-veins. However, most of our measurements of $H$. ovalis and $H$. major overlap (Table 1). This morphological plasticity could lead to underestimating seagrass biodiversity as mentioned in Nguyen et al. (2014). In the recent survey of the Gulf of Mannar, Puttalum Lagoon, and southern Sri Lanka (Ranahewa et al., 2018; Ranatunga \& Pethiyagoda, 2015; Gunasekara, 2017), H. major may mistakenly be identified as H. ovalis. In addition, our phylogenetic analysis also points out that $H$. major could be widely distributed in Sri Lanka, since plants collected from Mannar and Matara are identified as H. major. Potential hybrids from

243 Puttalum Lagoon have both $H$. ovalis and H. major ITS sequences, which may indicate the presence of $H$. major actually occurring where we failed to collect it. The ITS phylogenetic tree also showed that the H. decipiens like plants (Halophila sp. 2) collected from the Gulf of Mannar are distinct from H. decipiens in Taiwan. Conversely, rbcL sequences derived from H. decipiens 
247 like plants cluster with $H$. stipulacea collected from India. This incongruence could possibly 248 result in erroneous identifications since Halophila sp. 2 resembles H. stipulacea in the field. 249 Another possible explanation is the lack of genetic variation on the rbcL chloroplast gene, which 250 failed to resolve species boundaries in the genus Halophila (Lucas et al., 2012). The present 251 study also shows that there are only six parsimony informative sites across seven Halophila 252 species among $440 \mathrm{bp}$.

253 PCA analyses based on morphology show that Halophila sp.1 (allied to H. minor) and Halophila 254 sp. 2 (H. decipiens like) can be separated from other categories. Although Halophila sp. 2 is very 255 256 257 258 259 260 261 262 263 similar to H. stipulacea in appearance, most measurements are smaller than plants in the Mediterranean Sea (Procaccini et al., 1999) as well as those described as H. decipiens in Kuo et al (2006). As mentioned by Den Hartog (1970), Indian Ocean H. stipulacea plants often have delicate and membranous but never bullate leaves, and more or less deciduous stipules. These plants were initially collected by Isaac Bailey Balfour during the Transit of Venus expedition at Rodrigues Island in 1874 (Balfour, 1879), and later described as Halophila balfourii Soler. (Solereder, 1913). Currently, it is treated as a synonym of Halophila stipulacea (Forsskål) Ascherson. Therefore, the plants collected from the Gulf of Mannar could be H. balfourii. However, further genetic analyses from a broad sampling across its current distribution, including the population from the type locality of H. stipulacea and H. decipiens in the Red Sea, is needed to clarify the identity of Halophila sp 2. Most Halophila sp.1 (allied to H. minor) measurements overlap with H. minor or H. ovate (Kuo \& Den Hartog, 2001), except that lamina width $(1.15-1.89 \mathrm{~mm})$ is smaller compared to these two species (H. minor: $3.5-6 \mathrm{~mm}$; H. ovata: 4-8 mm). Unfortunately, even by using combination loci including matK, rbcL, and trnH-psbA (Lucas et al. 2012) or ITS, rbcL, and matK (Nguyen et al., 2015), there was a failure to resolve species boundaries in the H. ovalis complex. Further comparative phylogenomic approaches (Liu et al., 2017; Yu et al., 2018) may be useful in resolving H. ovalis complex species boundaries.

272 Soltis \& Soltis (2009) suggested that natural hybridization could be an important creative force 273 and evolutionary process responsible for the increasing of angiosperm species diversity. The 274 incongruence between phylogenetic relationships constructed based on different markers can be 275 considered a signature of hybridization, as well as two divergent alleles of a single locus found in 276 one individual. Intra-species variation in ITS have been identified in many different plant groups, 277 which may hamper attempts to uncover accurate phylogenetic species relationships (Poczai \& 
278 Hyvönen, 2010). Meanwhile, the high intraspecific variation in ITS is considered as incomplete 279 concerted evolution driven by hybridization (Xu et al., 2017). Additionally, the maternal 280 inheritance of the chloroplast gene tree (i.e., rbcL tree in the present study) reflects only the 281 evolutionary processes of maternal lineages, which may mask genetic evidence of hybridization 282 (Okuyama et al., 2005; Soltis \& Soltis, 2009). Either of these reasons may cause incongruence 283 between ITS and plastid phylogenies. Among marine angiosperms, natural hybridization has 284 been observed in only four genera (Halodule, Ruppia, Posidonia, and Zostera) (Ito \& Tanaka, 285 2011; Coyer et al., 2008; Martínez-Garrido et al., 2016; Sinclair et al. 2019). Ito \& Tanaka 286 (2011) found sympatric Halodule uninervis and $H$. pinifolia hybridizing in the waters of 287 Okinawa by reconstructing their phylogenetic relationship with rbcL and psbA-trnH loci. The 288 congruent pattern between morphological traits and nuclear loci was also observed in two 289 sympatric species of Posidonia (P. australis and P. coriacea) in Australia that show signs of 290 hybridization (Sinclair et al., 2019). In the present study, the majority of Halophila samples 291 collected from Kapitya failed to sequence due to multiple templates found in single plants, but 17 292 pure sequences in the ITS region were obtained with further cloning. Phylogenetic analyses 293 showed that a single plant contained ITS sequences clustered with both $H$. ovalis and H. major 294 (Figure 2). The percentage of sequencing failure due to multiple templates varied among the 295 three sites (22/32 at Kalpitiya, 1/35 at Mannar, and 5/33 at Matara), indicating that hybridization 296 may be common at these three sites, especially Kalpitiya. However, the PCA plot based on 297 morphology showed that most traits overlap among hybrid, H. ovalis, and H. major. This may be 298 due to the morphological plasticity found in Halophila (Hartog \& Kuo, 2006; Kuo et al., 2006; 299 Singh et al., 2019).

300

\section{Conclusions}

302 In conclusion, Halophila plants collected from Sri Lanka cluster into three clades by the ITS tree, 303 represented as H. major, H. ovalis complex, and Halophila sp. 2 clade. H. major is recorded as a new species of the genus Halophila in Sri Lanka, and may have a wide distribution and possibly be misidentified as $H$. ovalis in the previous literature. Meanwhile, $H$. decipiens like plants collected from Mannar may represent a cryptic species of either H. stipulacea or H. decipiens based on phylogenetic relationship traits shared among them. Surprisingly, we found the first case of hybridization in the genus Halophila, which may be a cross between $H$. ovalis and $H$. 
309

310

31

312 taxonomic status of Halophila sp. 1 and sp. 2.

313

314

315

316

317

318

319

320

321

322

323

324

325

326

327

328

329

330

331

332

333

334

335

336

337

338

\section{Acknowledgements}

\section{References}

Springer, Dordrecht 1-23. (pp. 645) Lanka, RISCON 2017. waters of Korea. PloS one, 12(5), e0177772. research methods, 33, 31-58.

major. Further phylogeographic study with a broader sampling scheme that includes plants from type localities and applying methods based on massive parallel sequencing (i.e., Hyb-Seq, review in $Y u$ et al., 2018) that can obtain genome wide genetic variation is needed to clarify the

We would like to thank the Department of Wildlife Conservation for issuing the permit to collect seagrass samples from Sri Lankan waters. Special thanks to Dr. John Kuo for his feedback on the preliminary draft and Mr. M.A.K. Peiris for assistance during the 2018 field trip.

Den Hartog, C. (1970). The sea-grasses of the world. North-Holland, Amsterdam. (pp. 257).

Den Hartog, C., \& Kuo, J. (2007). Taxonomy and biogeography of seagrasses. In: Larkum, A.W.D., Orth, R.T., \& Duarte, C.M. eds. Seagrasses: biology, ecology and conservation.

Gunasekara, R. (2017). Floral and faunal diversity in selected seagrass beds in the southern Sri

Hammer, Ø., Harper, D. A., \& Ryan, P. D. (2001). PAST: Paleontological statistics software package for education and data analysis. Palaeontologia electronica, 4(1), 9.

Kim, Y. K., Kim, S. H., Yi, J. M., Kang, C. K., Short, F., \& Lee, K. S. (2017). Genetic identification and evolutionary trends of the seagrass Halophila nipponica in temperate coastal

Kuo, J., \& Den Hartog, C. (2001). Seagrass taxonomy and identification key. Global seagrass 
339 Kuo, J., Kanamoto, Z., Iizumi, H., \& Mukai, H. (2006). Seagrasses of the genus Halophila

340 Thouars (Hydrocharitaceae) from Japan. Acta Phytotaxonomica et Geobotanica, 57(2), 129-154.

341

342 Kurniawan, F., Imran, Z., Darus, R. F., Anggraeni, F., Damar, A., Sunuddin, A., ... \& Iswantari, 343 A. (2020). Rediscovering Halophila major (Zollinger) Miquel (1855) in Indonesia. Aquatic

344 Botany, 161, 103171.

345

346

Liu, M., Zhao, J., Wang, J., Liu, Z., \& Liu, G. (2017). Phylogenetic analysis of 25 plant species

347

representing 19 angiosperm families and one gymnosperm family based on 390 orthologous

348

genes. Plant Systematics and Evolution, 303(3), 413-417.

349

350

Lucas, C., Thangaradjou, T., \& Papenbrock, J. (2012). Development of a DNA barcoding system

351

for seagrasses: successful but not simple. PLoS One, 7(1), e29987..

352

353

Mtwana Nordlund, L., Koch, E. W., Barbier, E. B., \& Creed, J. C. (2016). Seagrass ecosystem

354

services and their variability across genera and geographical regions. PLoS One, 11(10),

355 e0163091.

356

357 Newmaster, S. G., Fazekas, A. J., \& Ragupathy, S. (2006). DNA barcoding in land plants:

358 evaluation of rbcL in a multigene tiered approach. Botany, 84(3), 335-341.

359

360 Nguyen, V. X., Holzmeyer, L., \& Papenbrock, J. (2013). New record of the seagrass species

361 Halophila major (Zoll.) Miquel in Vietnam: evidence from leaf morphology and ITS analysis.

362 Botanica marina, 56(4), 313-321.

363

364 Nguyen, V. X., Detcharoen, M., Tuntiprapas, P., Soe-Htun, U., Sidik, J. B., Harah, M. Z.,

365 Prathep, A., \& Papenbrock, J. (2014). Genetic species identification and population structure of

366 Halophila (Hydrocharitaceae) from the Western Pacific to the Eastern Indian Ocean. BMC

367 Evolutionary Biology, 14(1), 92.

368

369 Nguyen, X. V., Höfler, S., Glasenapp, Y., Thangaradjou, T., Lucas, C., \& Papenbrock, J. (2015).

370 New insights into DNA barcoding of seagrasses. Systematics and Biodiversity, 13(5), 496-508.

Peer) reviewing PDF | (2020:04:47375:1:1:NEW 11 Aug 2020) 
371

372 Okuyama, Y., Fujii, N., Wakabayashi, M., Kawakita, A., Ito, M., Watanabe, M., ... \& Kato, M. 373 (2005). Nonuniform concerted evolution and chloroplast capture: heterogeneity of observed 374 introgression patterns in three molecular data partition phylogenies of Asian Mitella 375 (Saxifragaceae). Molecular Biology and Evolution, 22(2), 285-296.

376

377 Poczai, P., \& Hyvönen, J. (2010). Nuclear ribosomal spacer regions in plant phylogenetics:

378 problems and prospects. Molecular biology reports, 37(4), 1897-1912.

379

380 Procaccini, G., Acunto, S., Fama P., \& Maltagliati, F. (1999) Morphological and genetic

381 variability of Mediterranean populations of Halophila stipulacea (Forssk.) Aschers.

382 (Hydrocharitaceae) at different spatial scale. Marine Biology, 135, 181-189

383

384 Ranatunga, R. R. M. K. P., \& Pethiyagoda, P. D. R. S. (2015). Spatial Distribution and Species 385 Composition of Seagrasses in Mannar Lagoon. Proceedings of the Twentieth Inter Forestry and 386 Environment Symposium.

387

388

Ranahewa, T. H., Gunasekara, A. J. M., Premarathna, A. D., Karunarathna, S. C., \& Jayamanne, 389 S. C. (2018). A Comparative Study on the Diversity of Seagrass Species in Selected Areas of 390 Puttalam Lagoon in Sri Lanka. Journal of Oceanography and Marine Research, 6(185), 2.

391

392

Ruiz, H., \& Ballantine, D. L. (2004). Occurrence of the seagrass Halophila stipulacea in the 393 tropical West Atlantic. Bulletin of Marine Science, 75(1), 131-135.

394

395 Singh, S., Southgate, P. C., \& Lal, M. M. (2019). Morphological plasticity in a Fijian Seagrass:

396 Halophila ovalis subsp. bullosa. Regional Studies in Marine Science, 32, 100809.

397

398 Shimada, S., Watanabe, M., Ichihara, K., \& Uchimura, M. (2012). Morphological variations of 399 seagrass species, Halophila nipponica (Hydrocharitaceae, Alismatales). Coastal marine science, $400 \quad 35,85-90$.

401

Peer) reviewing PDF | (2020:04:47375:1:1:NEW 11 Aug 2020) 
402 Short, F. T., Moore, G. E., \& Peyton, K. A. (2010). Halophila ovalis in the tropical Atlantic 403 Ocean. Aquatic Botany, 93(3), 141-146.

404

405 Short, F. T., Polidoro, B., Livingstone, S. R., Carpenter, K. E., Bandeira, S., Bujang, J. S., ... \&

406 Erftemeijer, P. L. (2011). Extinction risk assessment of the world's seagrass species. Biological

407 Conservation, 144(7), 1961-1971.

408

409

Solereder, H. (1913). Systematisch-anatomische Untersuchung des Blattes der Hydrocharitaceen.

410

Beihefte zum Botanischen Centralblatt, 30, 24-104.

411

412

Soltis, P. S., \& Soltis, D. E. (2009). The role of hybridization in plant speciation. Annual review 413 of plant biology, 60, 561-588.

414

415 Tuntiprapas, P., Shimada, S., Pongparadon, S., Prathep, A., Saensouk, P., Theerakulpisut, P., ...

416 \& Kerdphol, R. (2015). Is Halophila major (Zoll.) Miquel a big H. ovalis (R. Brown) JD Hooker?

417 An evaluation based on age, morphology, and ITS sequence. Science Asia, 41(2), 79-86.

418

419 Udagedara, S., Fernando, D., Perera, N., Tanna, A., \& Bown, R. (2017). A first record of

420 Halodule pinifolia Miki den Hartog, and new locality of nationally endangered Halophila

421 beccarii Asch, from the eastern coast of Sri Lanka. International Journal of Aquatic Biology,

$4225(5), 328-335$.

423

424 Vera, B., Collado-Vides, L., Moreno, C., \& van Tussenbroek, B. I. (2014). Halophila stipulacea

425 (Hydrocharitaceae): a recent introduction to the continental waters of Venezuela. Caribbean

426 Journal of Science, 48(1), 66-70.

427

428 Waycott, M., Duarte, C. M., Carruthers, T. J., Orth, R. J., Dennison, W. C., Olyarnik, S., ... \&

429 Kendrick, G. A. (2009). Accelerating loss of seagrasses across the globe threatens coastal

430 ecosystems. Proceedings of the national academy of sciences, 106(30), 12377-12381.

431

432 Xu, B., Zeng, X. M., Gao, X. F., Jin, D. P., \& Zhang, L. B. (2017). ITS non-concerted evolution 
433 and rampant hybridization in the legume genus Lespedeza (Fabaceae). Scientific Reports, 7(1), 434 1-15.

435

436 Yu, X., Yang, D., Guo, C., \& Gao, L. (2018). Plant phylogenomics based on genome-

437 partitioning strategies: Progress and prospects. Plant diversity, 40(4), 158-164.

438

439 Figure 1. Sample collection sites coded with different colors (blue: Mannar, gray: Kalpitiya, and 440 black: Matara) for Halophila surveys in Sri Lanka. Numbers in brackets indicate sample size.

441 Figure 2. Comparison of leaf morphology of H. major, H. ovalis, and H. stipulacea like

442 specimens collected in Sri Lanka. Samples displayed in this figure were included and showed in 443 ITS tree (Figure 3).

444 Figure 3. Phylogeny of Halophila inferred from maximum likelihood and Bayesian analysis

445 based on 615 bp (including gaps) of nrDNA sequences comprising ITS-1, 5.8S rDNA and ITS-2.

446 Nodes are presented only for those with bootstrap scores $>90 \%$ majority rule for maximum

447 likelihood and $>90 \%$ majority probabilities for Bayesian probability values (ML /BI). Sequences

448 are color-coded based on different sampling locations as in Figure 1. Sample names with shading 449 are sequences derived from molecular cloning.

450 Figure 4. Phylogeny of Halophila inferred from maximum likelihood and Bayesian analysis

451 based on $440 \mathrm{bp}$ of the rbcL gene. Nodes are presented only for those with bootstrap scores $>$

$45290 \%$ majority rule for maximum likelihood and $>90 \%$ majority probabilities for Bayesian

453 probability values (ML /BI). Sequences are color-coded based on different sampling locations as 454 in Figure 1.

455 Figure 5. Component loadings for the first of two principal components of the PCA of 456 morphological traits with convex hull of different sample groups (LL: lamina length, LW: lamina 457 width, VA: crossed vein angle, DE: distance between marginal vein and lamina edge, LW / LL: 458 lamina width / lamina length, and HLW/DE: half lamina width/distance between marginal vein 459 and lamina edge).

460

461

462

463

Peer] reviewing PDF | (2020:04:47375:1:1:NEW 11 Aug 2020) 
Figure 1

Sample collection sites coded with different colors (blue: Mannar, green: Kalpitiya, and red: Matara) for Halophila surveys in Sri Lanka. Numbers in brackets indicate sample size.

Figure 1. Sample collection sites coded with different colors (blue: Mannar, green: Kalpitiya, and red: Matara) for Halophila surveys in Sri Lanka. Numbers in brackets indicate sample size.

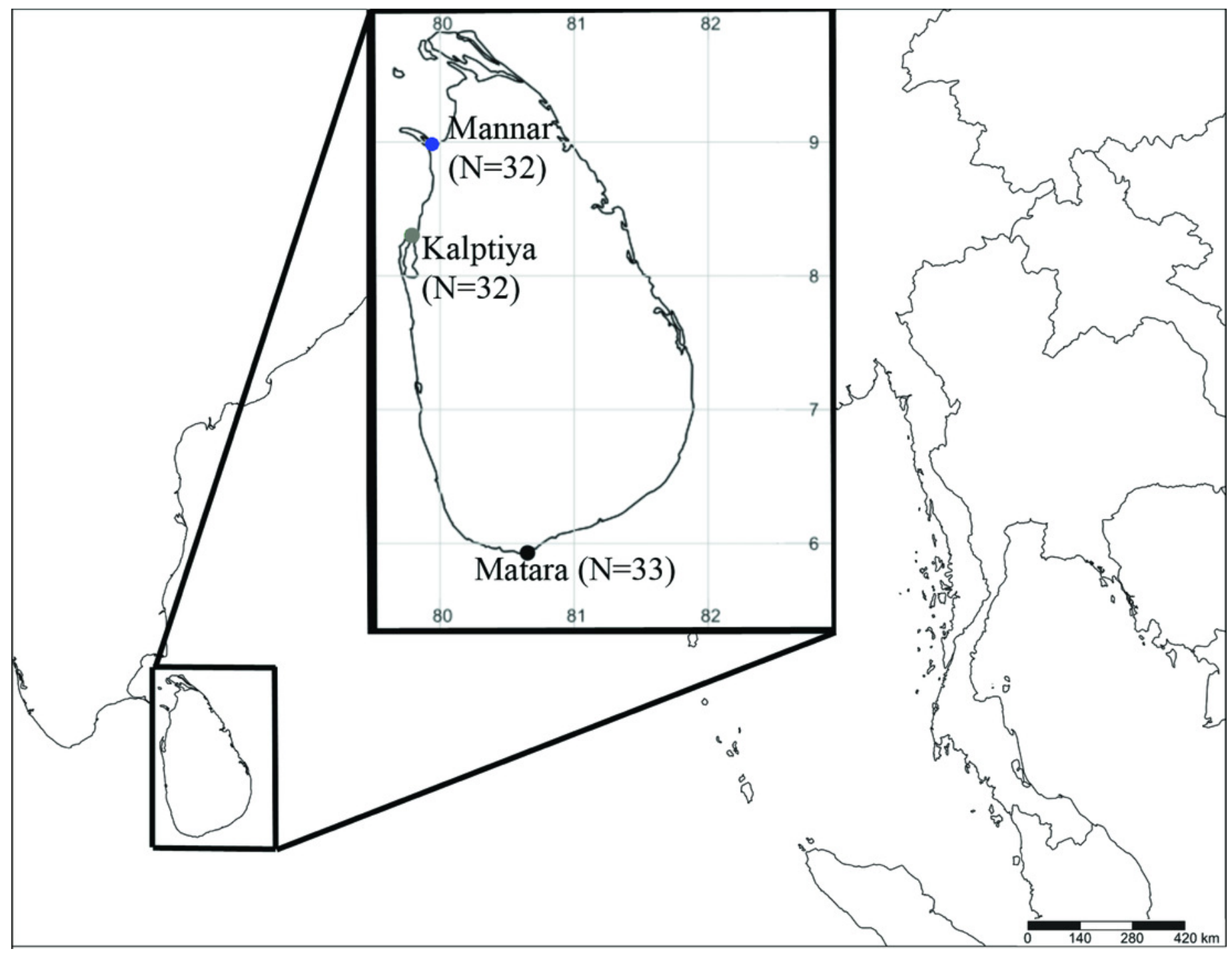




\section{Figure 2}

Comparison of leaf morphology of $H$. major, $H$. ovalis, and $H$. stipulacea like specimens collected in Sri Lanka. Samples displayed in this figure were included and showed in ITS tree (Figure 3).

Figure 2. Comparison of leaf morphology of $H$. major, $H$. ovalis, and $H$. stipulacea like specimens collected in Sri Lanka. Samples displayed in this figure were included and showed in ITS tree (Figure 3).

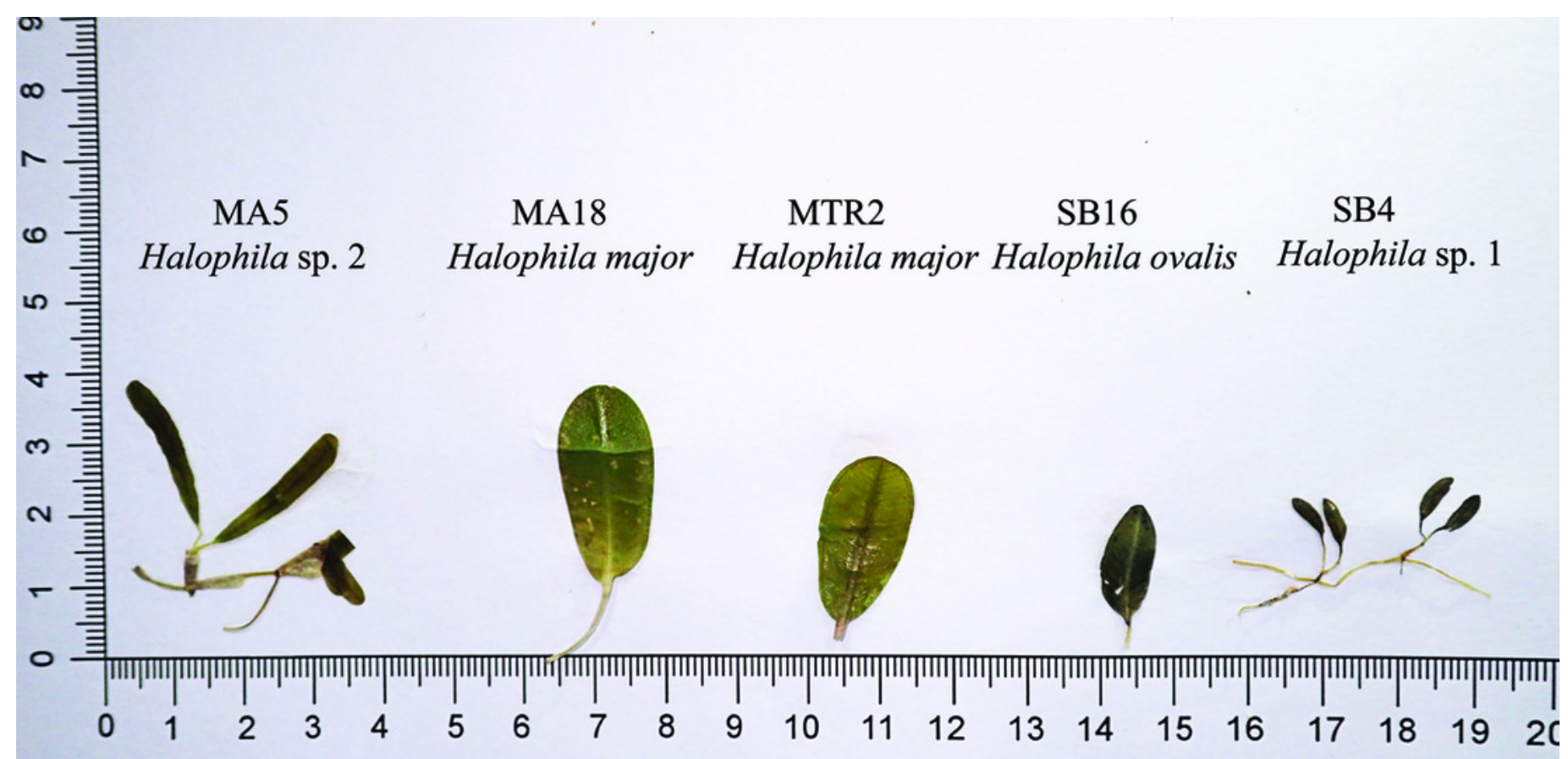




\section{Figure 3}

Phylogeny of Halophila inferred from maximum likelihood and Bayesian analysis based on 615 bp (including gaps) of nrDNA sequences comprising ITS-1, 5.8S rDNA and ITS-2. Nodes are presented only for those with bootstrap scores $>90 \%$ majority rule for

Figure 3. Phylogeny of Halophila inferred from maximum likelihood and Bayesian analysis based on 615 bp (including gaps) of nrDNA sequences comprising ITS-1, 5.8S rDNA and ITS-2. Nodes are presented only for those with bootstrap scores $>90 \%$ majority rule for maximum likelihood and $>90 \%$ majority probabilities for Bayesian probability values (ML /BI). Sequences are color-coded based on different sampling locations as in Figure 1. Sample names with shading are sequences derived from molecular cloning. 
- MTR (Matara)

- MA (Mannar)

- SB (Kalptiya)

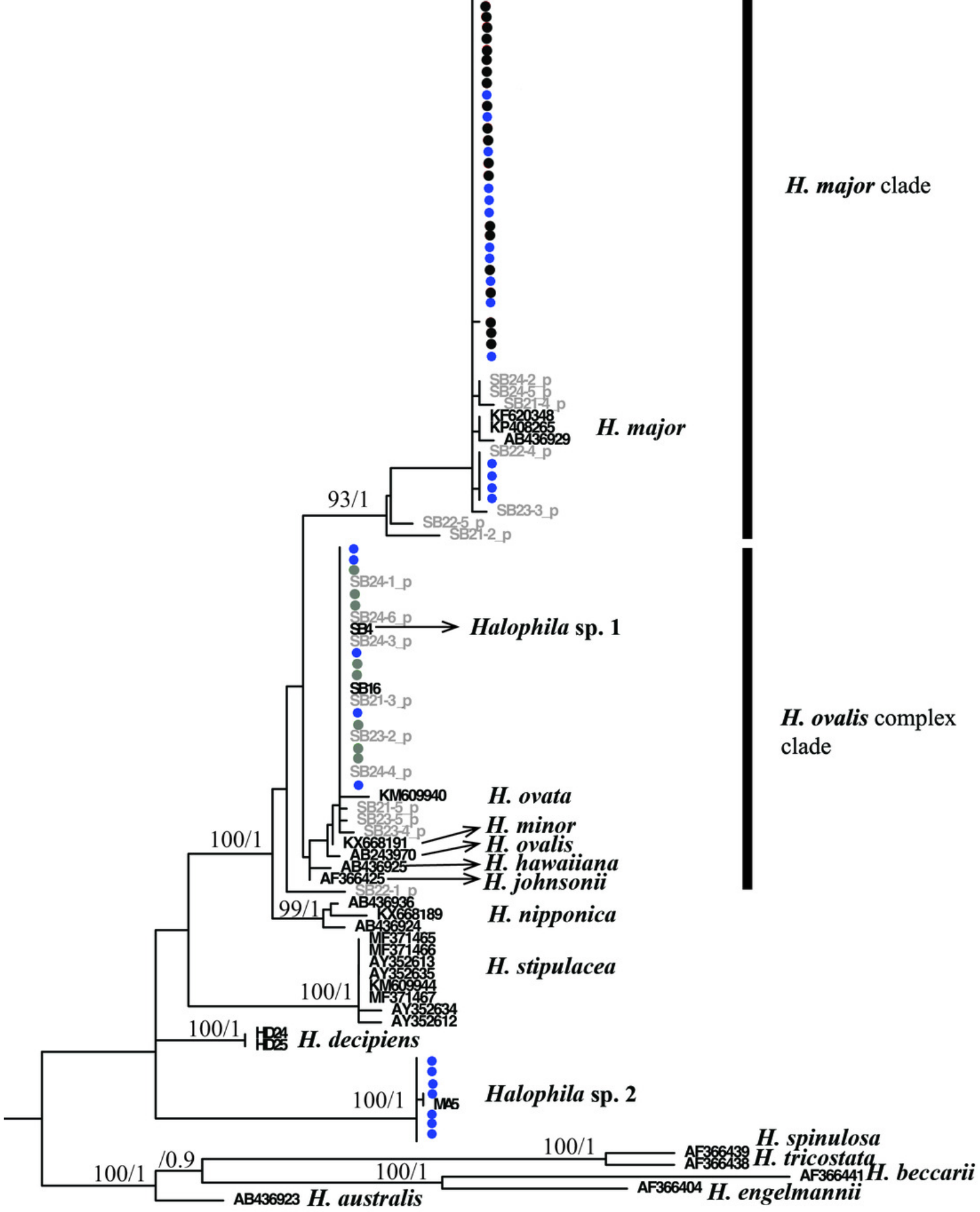

0.03 


\section{Figure 4}

Phylogeny of Halophila inferred from maximum likelihood and Bayesian analysis based on $440 \mathrm{bp}$ of the $\mathrm{rbcL}$ gene. Nodes are presented only for those with bootstrap scores $>$ $90 \%$ majority rule for maximum likelihood and $>90 \%$ majority probabilities for

Figure 4. Phylogeny of Halophila inferred from maximum likelihood and Bayesian analysis based on $440 \mathrm{bp}$ of the $\mathrm{rbcL}$ gene. Nodes are presented only for those with bootstrap scores

$>90 \%$ majority rule for maximum likelihood and > 90\% majority probabilities for Bayesian probability values (ML /BI). Sequences are color-coded based on different sampling locations as in Figure 1. 
- MTR (Matara)

- MA (Mannar)

- SB (Kalptiya)

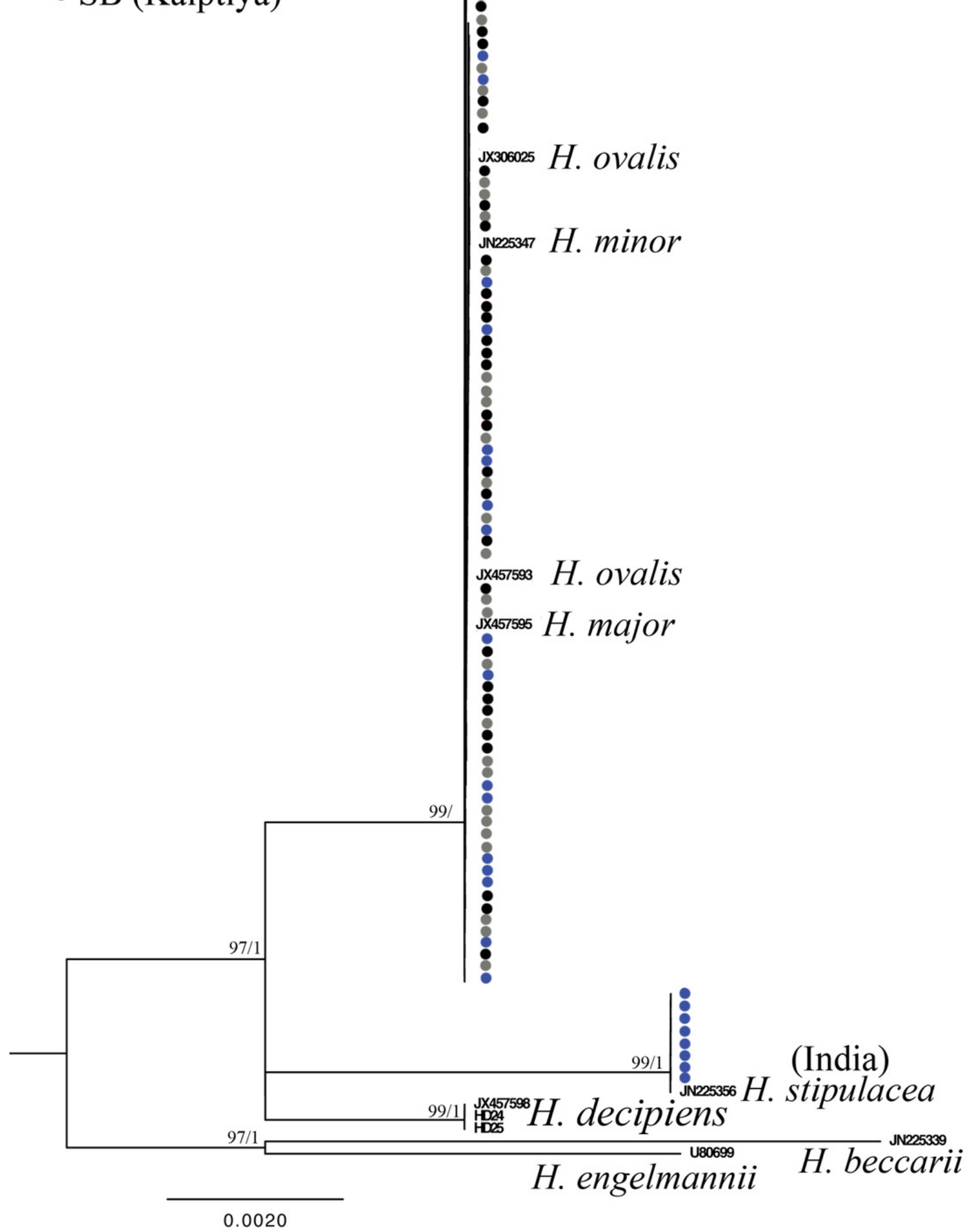




\section{Figure 5}

Component loadings for the first of two principal components of the PCA of morphological traits with convex hull of different sample groups (LL: lamina length, LW: lamina width, VA: crossed vein angle, DE: distance between marginal vein and lamina edge, $L$

Figure 5. Component loadings for the first of two principal components of the PCA of morphological traits with convex hull of different sample groups (LL: lamina length, LW: lamina width, VA: crossed vein angle, DE: distance between marginal vein and lamina edge, LW / LL: lamina width / lamina length, and HLW/DE: half lamina width/distance between marginal vein and lamina edge).

- Halophila major

$x$ Hybrid

$\times$ Potential hybrid

- Halophila ovalis

- Halophila sp.1

- Halophila sp.2

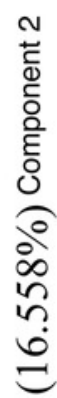

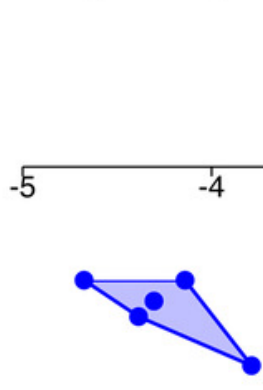

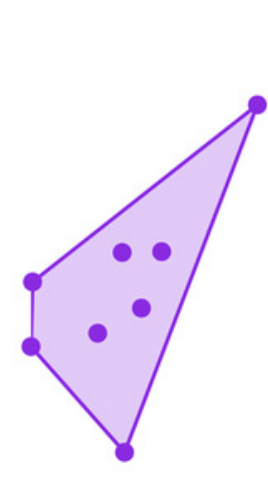

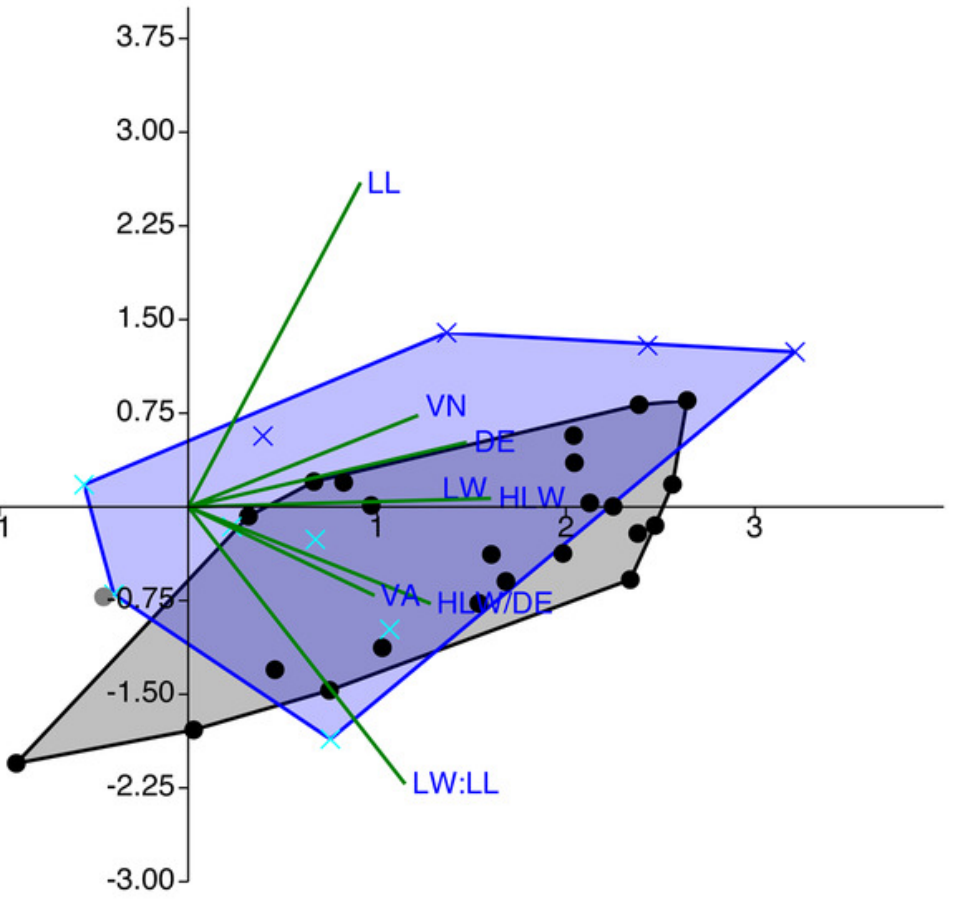

Component $1(63.026 \%)$ 


\section{Table $\mathbf{1}$ (on next page)}

Comparisons of leaf morphology of $H$. major, $H$. ovalis, and $H$. stipulacea like species collected in Sri Lanka and previous studies.

Table 1. Comparisons of leaf morphology of $H$. major, $H$. ovalis, and $H$. stipulacea like species collected in Sri Lanka and previous studies. 
1 Table 1: Comparisons of leaf morphology of H. major, H. ovalis, and H. stipulacea like species collected in Sri Lanka and previous 2 studies.

3

4

\begin{tabular}{|c|c|c|c|c|c|c|c|c|c|c|c|}
\hline Characteristic & $\begin{array}{l}\text { Species } \\
\text { H. ovalis }\end{array}$ & & & & & H. major & & & H. stipulacea & H. decipiens. & Halo \\
\hline & den Hartog (1970) & $\begin{array}{l}\text { Halophila sp. } \\
1 \text { (SB) }\end{array}$ & H. ovalis (SB) & $\begin{array}{l}\text { Potential } \\
\text { hybrid (SB) }\end{array}$ & Hybrid (SB) & $\begin{array}{l}\text { Kuo et al. } \\
\text { (2006) }\end{array}$ & $\begin{array}{l}\text { H. major } \\
\text { (MTR) }\end{array}$ & $\begin{array}{l}\text { H. major } \\
\text { (MA) }\end{array}$ & $\begin{array}{l}\text { Procaccini et } \\
\text { al. } 1999 \text {, Vera } \\
\text { et al. } 2014\end{array}$ & $\begin{array}{l}\text { Kuo et al. } \\
\text { (2006) }\end{array}$ & $\begin{array}{l}\text { H. } d \epsilon \\
\text { like }\end{array}$ \\
\hline $\begin{array}{l}\text { Number of } \\
\text { samples }\end{array}$ & & 5 & 2 & 6 & 4 & & 13 & 10 & & & \\
\hline $\begin{array}{l}\text { Lamina length } \\
(\mathrm{mm})\end{array}$ & $10-40$ & $4.42-6.61$ & $11.00-16.00$ & $12.00-20.00$ & $23.80-33.00$ & $15-25$ & $19.80-31.00$ & $8.05-31.13$ & $63.8-84.3$ & 20 & 17. \\
\hline $\begin{array}{l}\text { Lamina width } \\
(\mathrm{mm})\end{array}$ & $5-20$ & $1.15-1.89$ & $3.90-6.89$ & $6.55-9.90$ & $8.60-14.13$ & $9-11$ & $10.50-13.75$ & $4.72-14.63$ & $6.5-8.43$ & $4-6$ & 2 \\
\hline $\begin{array}{l}\text { No. of pair } \\
\text { cross veins }\end{array}$ & $10-25$ & $3-4$ & 13 & $11-17$ & $18-27$ & $14-17$ & $11-17$ & $12-18$ & $11-18$ & $6-9$ & \\
\hline Space between & & & & & & & & & 0.5 ( Ruiz \& & & \\
\hline $\begin{array}{l}\text { intramarginal } \\
\text { veins }(\mathrm{mm})\end{array}$ & $0.1-0.3$ & $0.09-0.17$ & $0.29-0.33$ & $0.34-0.51$ & $0.39-0.54$ & 0.2 & $0.50-0.72$ & $0.29-0.66$ & $\begin{array}{c}\text { Ballantine, } \\
\text { 2004) }\end{array}$ & $0.25-3$ & 0 . \\
\hline Cross-vein & $45-60^{\circ}$ & $46-68^{\circ}$ & $54 \circ$ & $58-82 \circ$ & $57-62 \circ$ & $45-60 \circ$ & $59-78 \circ$ & $57-80^{\circ}$ & $45-60 \circ$ & $\mathrm{n} / \mathrm{a}$ & \\
\hline
\end{tabular}


angles

\begin{tabular}{lccccccccccc} 
LW:LL & $\mathrm{n} / \mathrm{a}$ & $0.25-0.35$ & $0.43-0.35$ & $0.33-0.59$ & $0.33-0.43$ & $\mathrm{n} / \mathrm{a}$ & $0.44-0.56$ & $0.40-0.59$ & $\mathrm{n} / \mathrm{a}$ & $0.2-0.33$ & 0.8 \\
$\mathrm{HLW}: \mathrm{DE}$ & $0.5-0.63$ & $4.95-10.03$ & $10.51-6.75$ & $7.90-12.94$ & $10.29-13.25$ & $0.71-0.33$ & $9.01-12.69$ & $8.27-6.32$ & $\mathrm{n} / \mathrm{a}$ & $2-3$ & 4.9 \\
\hline
\end{tabular}

5

6

7 n/a: not available 